\title{
Mapping the Future of Occupations: Transformative and Destructive Effects of New Digital Technologies on Jobs
}

\author{
Frank Fossen \\ Associate Professor a; Research Fellow ${ }^{\text {b }}$ ffossen@unr.edu \\ Alina Sorgner \\ Assistant Professor c; Research Fellow ${ }^{\text {d; }}$ Research Affiliate ${ }^{b}$, asorgner@johncabot.edu \\ a University of Nevada, 1664 N Virginia St, Reno, NV 89557, U.S.A. \\ ${ }^{\mathrm{b}}$ Institute of Labor Economics (IZA), Schaumburg-Lippe-Straße 5-9, 53113 Bonn, Germany \\ ' John Cabot University, Via della Lungara, 233, 00165 Roma RM, Italy \\ ${ }^{d}$ Kiel Institute for the World Economy, Kiellinie 66, 24105 Kiel, Germany
}

\begin{abstract}
$\mathrm{W}$

e investigate the impact of new digital technologies upon occupations. We argue that these impacts may be both destructive and transformative. The destructive effects of digitalization substitute human labor, while transformative effects of digitalization complement it. We distinguish between four broad groups of occupations that differ with regard to the impact of digitalization upon them. "Rising star" occupations are characterized by the low destructive and high transformative effects of digitalization. In contrast,

"collapsing" occupations face a high risk of destructive effects. "Human terrain" occupations have low risks of both destructive and transformative digitalization, whereas "machine terrain" occupations are affected by both types. We analyze the differences between these four occupational groups in terms of the capabilities, which can be considered bottlenecks to computerization. The results help to identify which capabilities will be in demand and to what degree workers with different abilities can expect their occupations to be transformed in the digital era.
\end{abstract}

\section{Keywords:}

digital technologies;

digitalization;

artificial intelligence;

occupations; worker skills
Citation: Fossen F., Sorgner A. (2019) Mapping the Future of Occupations: Transformative and Destructive Effects of New Digital Technologies on Jobs. Foresight and STI Governance, vol. 13, no 2, pp. 10-18. DOI: 10.17323/25002597.2019.2.10.18. 
A $s$ the world of labor becomes increasingly digitized, many occupations face significant changes. On the one hand, these changes induce an increasing relative demand for certain skills that cannot be performed by digital machines. Demand also increases for skills that are necessary for interacting with digital technologies. On the other, occupations that require skills that can be substituted by these digital technologies may face a high risk of becoming obsolete. This paper presents a novel approach to conceptualizing the different effects of digitalization on occupations by arguing that occupations may be affected by transformative and destructive digitalization in distinct ways. We construct a map that illustrates the different impacts of digitalization upon occupations. We also analyze the composition of capabilities necessary in occupations that are affected by different aspects of digitalization to contribute to a better understanding of the skills that make workers more competitive in the digital era.

Previous studies that investigated the effects of digitalization on occupations mostly focused on the risk of the replacement of human workers by new digital technologies, that is, the destructive effects of digitalization. In particular, Frey and Osborne [Frey, Osborne, 2017] concluded that about 47 percent of the US labor force are currently in jobs that are highly likely to be replaced by machines in the next ten to twenty years. Other studies analyzing various countries largely confirm that new digital technologies are likely to replace a substantial share of the human workforce although the average risk of automation varies a lot across countries (see, e.g., [Arntz et al., 2017], for a study of OECD countries; [Manyika et al., 2017; Chang, Huynh, 2016], for an analysis of ASEAN countries, and [Sorgner et al., 2017], for an analysis of selected G20 countries).

Evidence on the transformative effects of digital technologies on occupations is, however, scarce. Felten et al. [Felten et al., 2018] developed a measure of advances in artificial intelligence that they link to abilities and occupations. Such transformative effects suggest that an occupation will experience substantial changes, including changes in the skill requirements for individuals working in this occupation, but machines will not necessarily replace the human workers (e.g., [Brynjolfsson et al., 2018]). The transformative effects of digitalization might also be related to stronger human-machine interactions (e.g., working with robots, applying AI to solve job-related tasks, etc.).

In this paper, we argue that digitalization impacts occupations in a gradual, two-dimensional way, rather than being either destructive or transformative. Indeed, the results of our empirical analysis suggest that about $75 \%$ of the employees in the United States are affected by either destructive or transformative digitalization, but not both, while the remaining 25\% are affected by both digitalization types or virtually unaffected by any type of digitalization. We also ana- lyze the differences in skill requirements between occupations differently affected by digitalization.

\section{Transformative and Destructive Effects of Digitalization on Occupations}

Previous studies have mainly focused on the destructive effects of digitalization, that is, the probability that human workers can be replaced by machines (e.g., [Brynjolfsson, McAfee, 2014; Acemoglu, Restrepo, 2019]). This literature finds that large shares of the workforce in the United States are active in occupations that either face a very high or a very low risk of destructive digitalization, while only a rather small share of workers are found in occupations that face a mid-level risk [Frey, Osborne, 2017].

In contrast, the transformative effects of digitalization, i.e., the extent to which digitalization will affect occupations without necessarily replacing human workers, received much less attention in the literature. Such transformative effects of digitalization may change the way people work in their occupation or occupational content, with a tendency to make human workers more productive. Usually, transformative digitalization is discussed in connection with the complementary effects of technology, that is, when there are extensive human-machine interactions [Autor, 2015].

It appears that destructive and transformative digitalization has already begun to impact labor markets, but they do so in different ways. In their analysis of labor market transitions in the United States, Fossen and Sorgner [Fossen, Sorgner, 2019] demonstrate that destructive digitalization triggers individual transitions into unemployment and unincorporated, necessity-driven entrepreneurship, whereas transformative digitalization facilitates incorporated, opportunitydriven entrepreneurship. A study by Sorgner [Sorgner, 2017], which focuses on the impacts of destructive digitalization on individual labor market transitions in Germany, arrives at similar results.

It is plausible to assume that occupations are not affected by digitalization in a purely destructive or transformative way. Instead, occupations rather differ from each other gradually in terms of digitalization's impact on them, thus, implying that an occupation might face different levels of transformative and destructive risks at the same time.

Figure 1 demonstrates this idea visually by plotting all occupations on a two-dimensional chart where the horizontal axis represents destructive effects and the vertical axis represents the transformative effects of digitalization on occupations. In this way, all occupations can be divided into four major groups that describe the extent to which an occupation is affected by both transformative and destructive digitalization. The group "rising stars" in Quadrant I consists of occupations upon which transformative digitalization has a high impact, but in these occupations, this 
Figure 1. Effects of Digitalization on Occupations

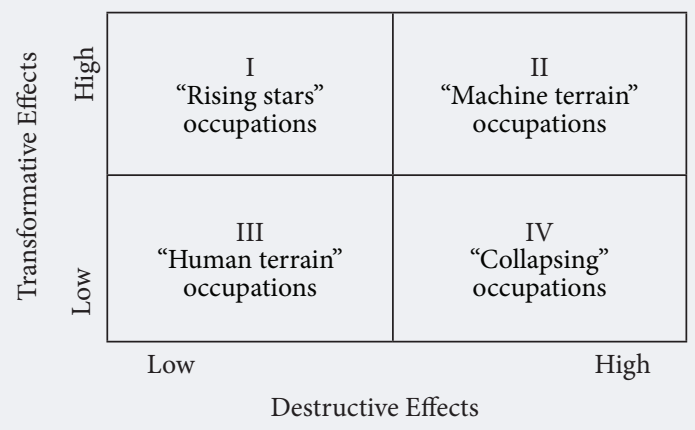

Source: compiled by the authors.

does not lead to the replacement of human workers, so the risk of destructive digitalization is low. These occupations are facing significant changes in terms of work processes due to digitalization and, consequently, in terms of skill requirements. However, not all tasks performed in these occupations can be taken over by machines. Therefore, human workers are not at risk of replacement, only the division of labor between humans and machines is changing. Individuals working in these occupations will need a high level of flexibility to be able to adjust to rapid changes in their occupations. It is also likely that there is great need for acquiring further qualification in such occupations.

The group "machine terrain" in Quadrant II consists of occupations that are characterized by high transformative and destructive impacts of digitalization simultaneously, which means that these occupations are transformed due to digital technologies in ways that could make human workers obsolete. The main difference between the occupations in the group "machine terrain" and those in the group "rising stars" is that digitalization transforms the work content of the "machine terrain" occupations in a more radical way, such that there remains almost no need for human workers.

Individuals in occupations that are part of the "human terrain" group (Quadrant III) are rather unlikely to be replaced by machines (low destructive digitalization effects). At the same time, digital technologies do not exert much transformative influence on these occupations either. Thus, it can be assumed that individuals in these occupations possess skills that cannot currently be performed by machines and there is little need for human-machine interactions in such occupations. Moreover, the progress in new digital technologies designed to overcome these bottlenecks in computerization might be relatively slow. Manual, non-routine tasks, especially those that need to be performed in unstructured environments, possibly constitute a major part of the tasks in these occupations.

Finally, the "collapsing" occupations (Quadrant IV) are occupations that face a high risk of destructive digitalization, in which there will be little need for "human" skills. In the future, it will be possible to automate these occupations nearly completely without even transforming the occupations substantially. These occupations are likely to consist of manual and cognitive routine tasks. The computerization of occupational tasks is rather straightforward in "collapsing" occupations.

To summarize, the four groups of occupations can be distinguished by the level of digitalization's impact, which can be either destructive, transformative, or both. It is also very likely that the groups are different concerning the skills of individuals working in these occupations. In the following empirical sections, we categorize occupations into the groups and analyze the differences between them.

\section{Data}

\section{Measures of the Impact of Digitalization on Occupations}

To map occupations according to the impact of digitalization, we use two measures of occupational susceptibility to digitalization that we interpret as destructive and transformative impacts. To measure destructive digitalization, we use computerization risks of occupations estimated by [Frey, Osborne, 2017]. The measure captures the risk of the replacement of human workers by machines in the next 10-20 years based on expert judgments and selected characteristics of occupations from the $\mathrm{O}^{\star} \mathrm{Net}$ database compiled by the US Department of Labor. ${ }^{1}$ In a first step, technology experts provided their estimates for 71 occupations concerning their susceptibility to automation in the next 20 years. In a second step, this list of hand-classified occupations was used as a training dataset for a machine learning algorithm that classified the remaining occupations in the $\mathrm{O}^{*} \mathrm{Net}$ database based on the job requirements identified as computerization bottlenecks.

As in [Fossen, Sorgner, 2019], we use a measure of past advances in AI developed by [Felten et al., 2018] as an indicator for transformative digitalization. This measure is based on the AI Progress Measurement dataset provided by the Electronic Frontier Foundation (EFF) in combination with $\mathrm{O}^{\star} \mathrm{Net}$ occupational data. In contrast to the measure of destructive computerization that predicts future developments, the measure of transformative digitalization is based on past developments (2010-2015) in 16 categories of $\mathrm{AI}^{2}{ }^{2}$

\footnotetext{
$\mathrm{O}^{\star} \mathrm{Net}$ is a database of quantitative indicators of occupational requirements, workforce characteristics, and occupation-specific information in the United States.

${ }^{2}$ Categories of $\mathrm{AI}$ are, for example, image recognition, speech recognition, and translation, among others.
} 
Table 1. Computerization Bottlenecks and Corresponding Variables from $\mathbf{O}^{\star} \mathrm{Net}$

\begin{tabular}{|c|c|c|}
\hline $\begin{array}{c}\text { Computerization } \\
\text { bottleneck }\end{array}$ & $\mathbf{O}^{\star N e t}$ variable & $\mathrm{O}^{\star}$ Net description \\
\hline \multirow[t]{3}{*}{$\begin{array}{l}\text { Perception and } \\
\text { manipulation }\end{array}$} & Finger dexterity & $\begin{array}{l}\text { The ability to make precisely coordinated movements of the fingers of one or } \\
\text { both hands to grasp, manipulate, or assemble very small objects. }\end{array}$ \\
\hline & Manual dexterity & $\begin{array}{l}\text { The ability to quickly move your hand, your hand together with your arm, or } \\
\text { your two hands to grasp, manipulate, or assemble objects. }\end{array}$ \\
\hline & $\begin{array}{l}\text { Cramped work space, } \\
\text { awkward positions }\end{array}$ & $\begin{array}{l}\text { How often does this job require working in cramped work spaces that requires } \\
\text { getting into awkward positions? }\end{array}$ \\
\hline Creative intelligence & Originality & $\begin{array}{l}\text { The ability to come up with unusual or clever ideas about a given topic or } \\
\text { situation, or to develop creative ways to solve a problem. }\end{array}$ \\
\hline \multirow[t]{4}{*}{ Social intelligence } & Social perceptiveness & Being aware of others' reactions and understanding why they react as they do. \\
\hline & Negotiation & Bringing others together and trying to reconcile differences. \\
\hline & Persuasion & Persuading others to change their minds or behavior. \\
\hline & $\begin{array}{l}\text { Assisting and caring for } \\
\text { others }\end{array}$ & $\begin{array}{l}\text { Providing personal assistance, medical attention, emotional support, or other } \\
\text { personal care to others such as coworkers, customers, or patients. }\end{array}$ \\
\hline \multicolumn{3}{|c|}{$\begin{array}{l}\text { Note. This table was adopted from [Frey, Osborne, 2017]. These authors also include a variable "fine arts" as part of the bottleneck "creative intelligence". } \\
\text { We do not use this variable in our analysis because it is coded as "irrelevant" for more than half of the occupations in O*Net. }\end{array}$} \\
\hline
\end{tabular}

These AI categories are linked to 52 distinct abilities that $\mathrm{O}^{\star} \mathrm{Net}$ uses to describe job requirements. This way, the authors estimated progress scores in AI performance for each occupation.

Both measures of destructive and transformative digitalization are available at the 6-digit code level of the System of Occupational Classification (SOC). For 751 occupations from $\mathrm{O}^{\star} \mathrm{Net}$, we were able to merge both the measures of the computerization probability and of advances in AI.

\section{Occupation-Specific Characteristics}

Our measures of occupation-specific characteristics that we use to describe the occupations also stem from the $\mathrm{O}^{\star} \mathrm{Net}$ database. We use $\mathrm{O}^{\star} \mathrm{Net}$ variables corresponding to the bottlenecks to computerization, as defined by [Frey, Osborne, 2017]. These authors identify three broad areas of capabilities that are particularly difficult for machines: perception and manipulation, creativity, and social intelligence. Table 1 lists and describes these variables. We assume that these occupational characteristics are the most important for distinguishing between the four groups of occupations that differ with regard to the impact of digitalization, since they represent capabilities that are likely to be in high demand in the future due to their low susceptibility to digitalization.

\section{Results}

\section{Descriptive Statistics for Digitalization Impact Measures}

Descriptive statistics of both measures of digitalization are shown in Table 2. The destructive digitalization measure takes values between 0 and 1 , reflecting its probabilistic nature. The transformative measure is an index that takes positive values but does not allow for straightforward interpretation. Larger values of this measure indicate more pronounced advances in $\mathrm{AI}$ in a particular occupation, which we interpret in terms of the stronger transformative impact of digitalization upon that occupation.

We argue that both digitalization measures capture different impacts on occupations. This is supported by Figures 2 and 3, which show the distributions of the measures of destructive and transformative digitalization, respectively. The measure of destructive digitalization, which is operationalized by the computerization probabilities, has a pronounced U-shaped distribution suggesting that a large share of all occupations face either a very high or a very low risk of destructive computerization (Figure 2). The share of occupations with middling levels of computerization risk is rather low. At the same time, our measure of transformative digitalization, which is operationalized as advances in AI, has a well-pronounced bell-shaped distribution (Figure 3 ). This means that a large share of all occupations face moderate levels of transformation due to digitalization, while only few occupations face a very strong risk of transformative digitalization or will remain almost unaffected. However, there are several occupations in our sample (airline pilots, air traffic controllers, surgeons, and physicians) with impact scores of transformative digitalization that are more than three standard deviations above the population mean. Indeed, these occupations face a very strong impact from transformative digitalization, but they are unlikely to disappear, since the destructive digitalization risk for these occupations is very low to moderate. Last but not least, a large negative correlation coefficient between both digitalization measures 


\section{Table 2. Descriptive Statistics} of Digitalization Measures

\begin{tabular}{|l|c|c|}
\hline $\begin{array}{l}\text { Impact of } \\
\text { digitalization: }\end{array}$ & $\begin{array}{c}\text { Destructive } \\
\text { digitalization }\end{array}$ & $\begin{array}{c}\text { Transformative } \\
\text { digitalization }\end{array}$ \\
\hline Operationalization: & $\begin{array}{c}\text { Computerization } \\
\text { probabilities } \\
\text { Frey, Osborne, } \\
\text { 2017] }\end{array}$ & $\begin{array}{c}\text { Advances in AI } \\
\text { [Felten et al., 2018] }\end{array}$ \\
\hline Mean & 0.579 & 3.170 \\
\hline Median & 0.690 & 3.164 \\
\hline Standard deviation & 0.371 & 0.706 \\
\hline Minimum & 0.003 & 1.417 \\
\hline Maximum & 0.990 & 6.537 \\
\hline $\begin{array}{l}\text { Number of } \\
\text { observations }\end{array}$ & 751 & 751 \\
\hline $\begin{array}{l}\text { Note: } \text { Values reported are weighted by the employment in each } \\
\text { occupation in the United States. } \\
\text { Source: compiled by the authors. }\end{array}$ \\
\hline
\end{tabular}

( $\rho=-0.48)$ further reflects that our measures capture different aspects of digitalization.

\section{Mapping the Effects of Digitalization on Occupations}

In this section, we map occupations according to the expected impact the new wave of digitalization will have upon them. We also describe the four major groups of occupations with respect to required capabilities, as outlined above.

Figure 4 shows our mapping of the occupations using the measures of destructive and transformative digitalization. We split the chart area into four quadrants at the median values of the two measures, weighted by US employment in the occupations (Table 2). The

\section{Figure 2. The Distribution of the Measure of Destructive Digitalization}

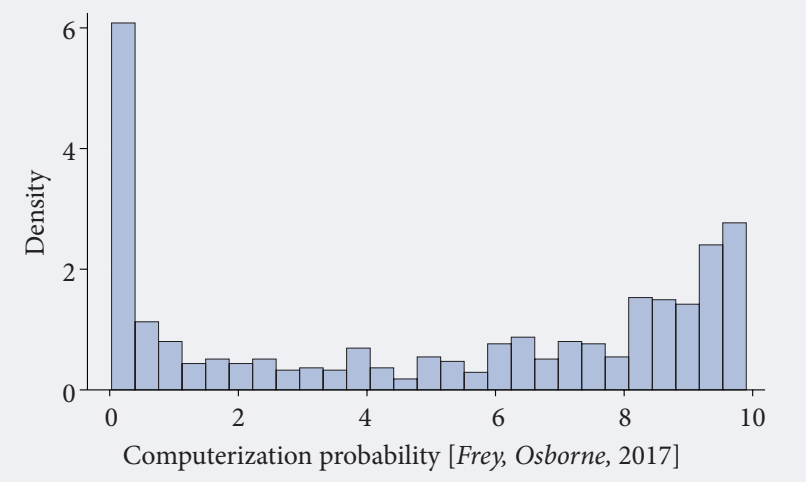

Source: compiled by the authors. majority of occupations fall either into the group "rising stars" or "collapsing" occupations, and thus, they face either high levels of transformative digitalization or they are severely affected by destructive digitalization, but not both. This is not very surprising given the strong negative correlation between the destructive and transformative digitalization measures. This observation is also compatible with the previous literature that discusses substitutive and complementary effects of digitalization on labor markets. However, there are also many occupations on the map that are strongly affected by both digitalization types ("machine terrain" occupations) or that are not affected by digitalization in any significant way ("human terrain" occupations). This result suggests that digitalization cannot be viewed as impacting occupations in an either destructive or transformative way. Rather, digitalization should be considered as having more gradual and complex effects upon occupations. While we suggest differentiating between the two dimensions here, future research might identify even more relevant dimensions.

Figure 4 further illustrates the employment shares in each quadrant that are indicated by the size of the bubbles, each of which represents one of 751 occupations. Employment shares are highest in the "rising stars" group (37\% of total employment in the United States) and the "collapsing" occupations group (38\%), while $11 \%$ of the workforce are employed in "machine terrain" occupations and $12 \%$ in "human terrain" occupations. ${ }^{3}$ Table 3 lists occupations with more than one million employees and those with very large or very low scores in the measure of advances in AI. These occupations are labeled in Figure 4 using the same occupation identification numbers as in the table.

\section{Figure 3. The Distribution of the Measure of Transformative Digitalization}

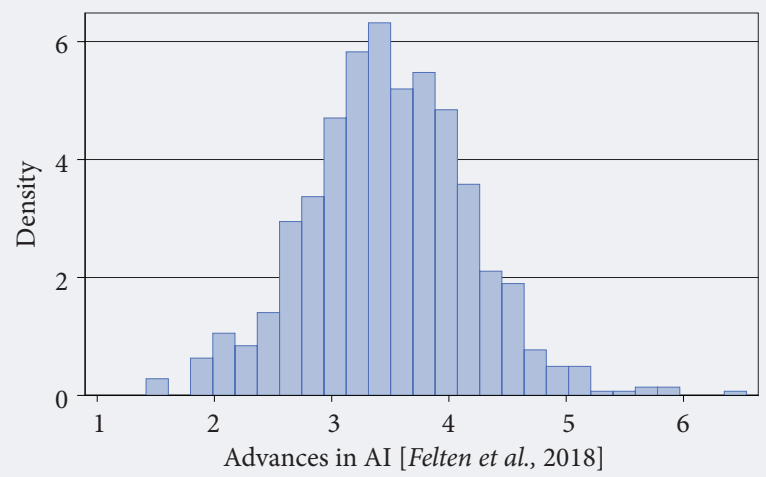

Source: compiled by the authors.

\footnotetext{
3 There is also a tiny share of employment (about 1\%) in occupations that have the weighted median level of computerization probabilities (destructive digitalization impact), and thus, we did not assign them to any quadrant. These occupations are housekeepers and painters of transportation equipment (both between "human terrain" and "collapsing occupations"), as well as light truck or delivery services drivers (at the intersection of lines representing median values of both digitalization measures).
} 


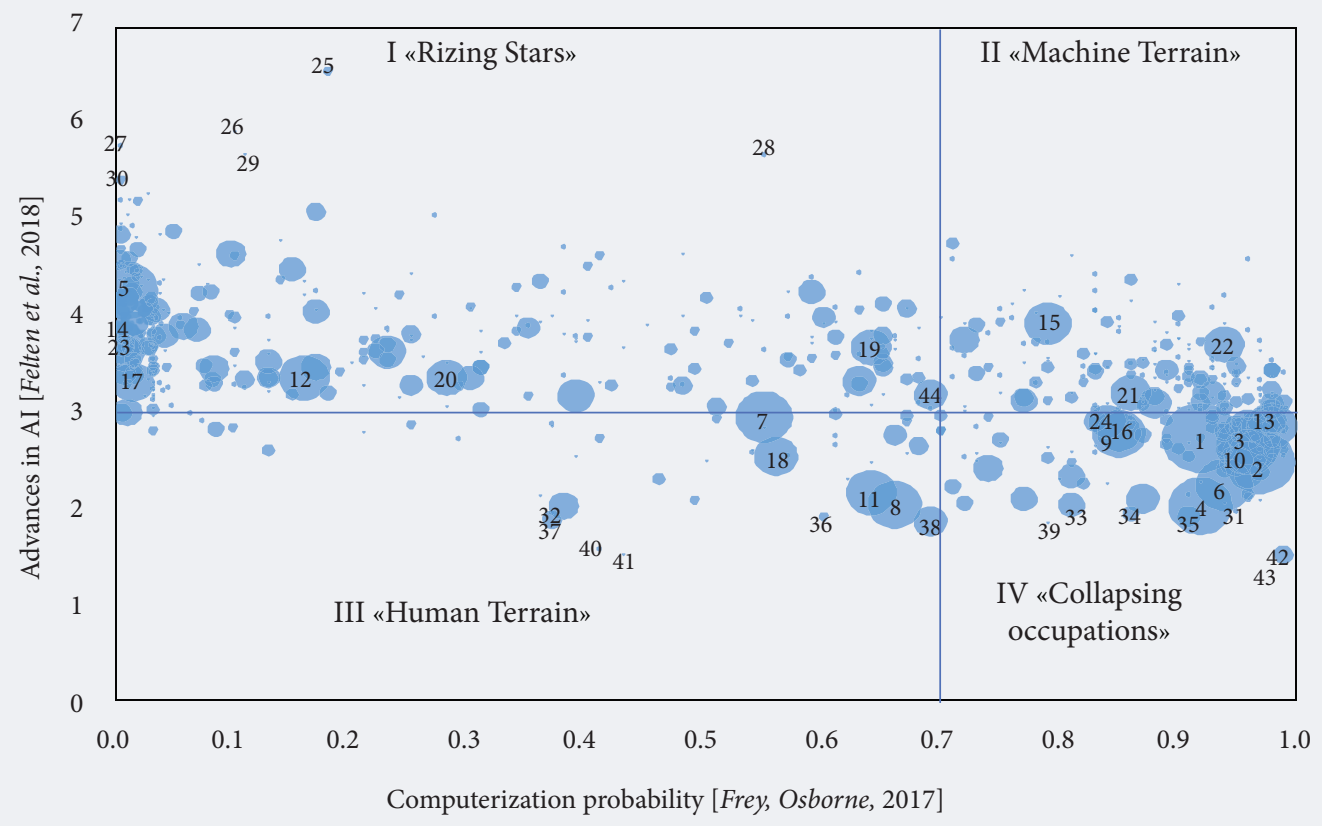

Note. Each bubble represents one occupation. The size of the bubbles reflects total US employment in the occupations. The horizontal and vertical lines represent median values of both measures of digitalization, weighted by employment. The map shows occupational identification numbers for selected occupations: occupations with employment of more than 1 million, occupations with very large or very low scores in advances in AI, and the occupation closest to the median scores of both digitalization measures. Table 3 provides details on these occupations.

Source: compiled by the authors.

In the next step, we analyzed the characteristics of the occupations in each quadrant. Specifically, we analyzed the level of capabilities needed in the occupations that currently constitute computerization bottlenecks, and thus, cannot be performed well by machines. We use the eight occupational characteristics that have been identified as computerization bottlenecks by [Frey, Osborne, 2017].

Table 4 shows the average required levels of each computerization bottleneck capability for the occupations in each quadrant. Values marked in boldface represent an above-average level as compared to the full sample. This table clearly demonstrates that "rising stars" occupations require above-average levels in almost all capabilities that currently constitute automation bottlenecks, and the level of these capabilities is below average in "collapsing" occupations. The only skill, for which we find an opposite result, is manual dexterity. Manual dexterity seems to be less important for "rising star" occupations than for collapsing occupations. This is probably due to recent developments in the technologies of Industry 4.0, in particular, industrial robots that achieve high levels of manual dexterity, which are comparable to those of humans. A sample of "collapsing" occupations can be found in the manufacturing sector, such as electro- mechanical equipment assemblers, but also in services, such as fast food preparation workers and waiters. Occupations in the group "machine terrain" that face high impacts of both destructive and transformative digitalization show above-average levels of such capabilities as working in a cramped workspace, manual dexterity, and finger dexterity. A typical occupation in this group is the occupation of heavy and tractortrailer truck drivers, which demands manual skills and is performed in unstructured environments. This occupation is likely to be replaced by machines in the future, because it faces strong transformation due to AI that allows for the development of self-driving vehicles. A less typical occupation in this group is executive secretaries and executive administrative assistants, who possess many characteristics of the "rising stars" occupations, such as above-average levels of social perceptiveness, assisting and caring for others, persuasion, and originality. However, due to the very strong transformative impact of AI, in particular, in areas of voice recognition and text recognition, these occupations face the risk of replacement in the future. An example of this development is the already existing AI scheduling assistant Amy, which is able to independently schedule meetings and communicate with humans. ${ }^{4}$ Thus, "machine terrain" occupations

https://x.ai/ 


\section{Table 3. The Impact of Digitalization upon Selected Occupations}

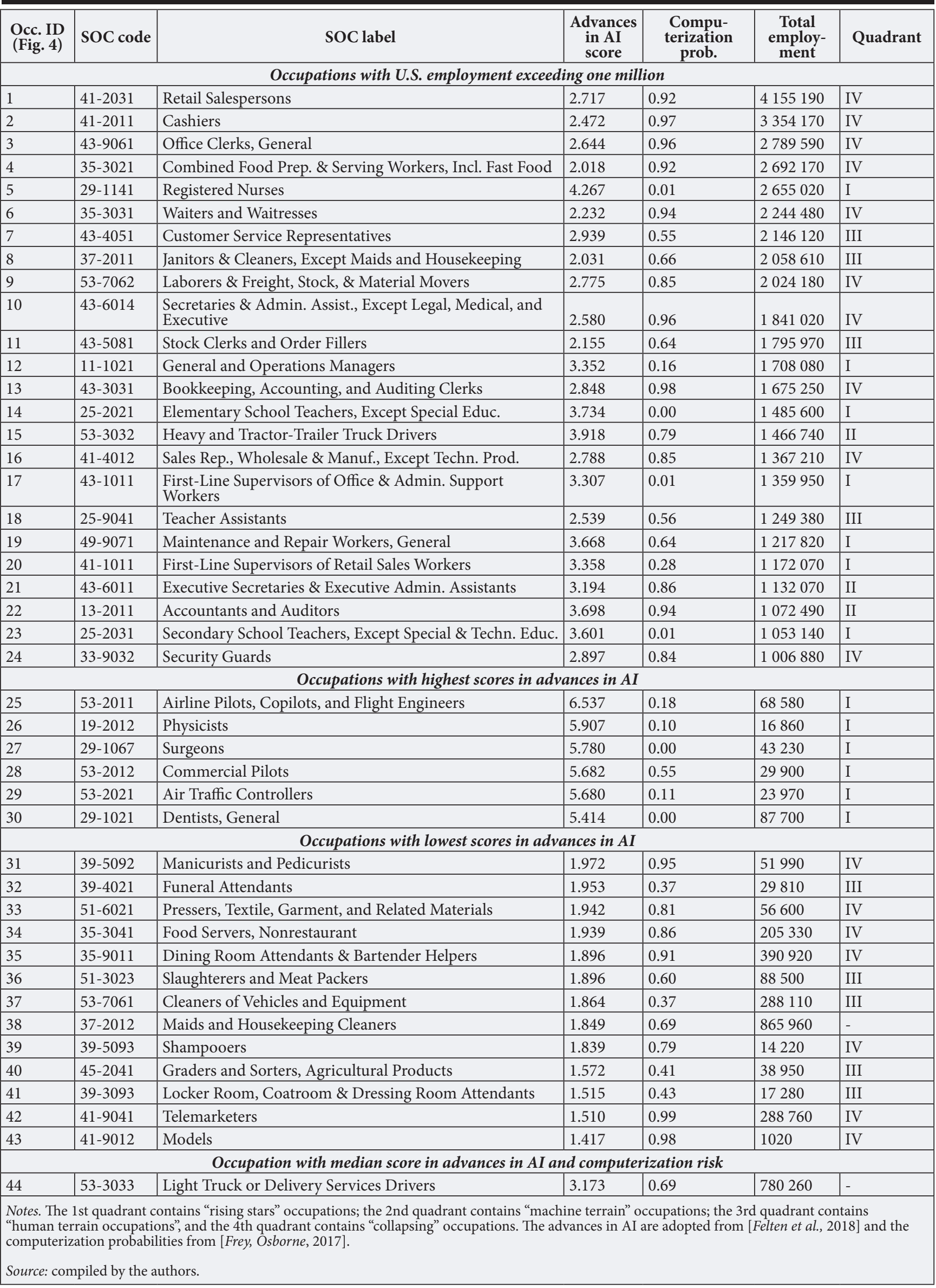


Table 4. Digitalization Impacts and Computerization Bottlenecks of Occupations by Quadrants

\begin{tabular}{|c|c|c|c|c|c|}
\hline Occupational group & "Rising stars" & $\begin{array}{l}\text { "Machine } \\
\text { terrain" }\end{array}$ & $\begin{array}{l}\text { "Human } \\
\text { terrain" }\end{array}$ & $\begin{array}{l}\text { "Collapsing } \\
\text { occupations" }\end{array}$ & \multirow[t]{2}{*}{ Total } \\
\hline Quadrant & Q1 & Q2 & Q3 & $\mathrm{Q} 4$ & \\
\hline \multicolumn{6}{|c|}{ Digitalization measures } \\
\hline Advances in AI [Felten et al., 2018] & 3.817 & 3.562 & 2.581 & 2.61 & 3.17 \\
\hline Computerization prob. [Frey, Osborne, 2017] & 0.186 & 0.865 & 0.477 & 0.916 & 0.579 \\
\hline \multicolumn{6}{|c|}{ Computerization bottlenecks } \\
\hline Finger Dexterity & 35.959 & 40.280 & 33.002 & 34.157 & 35.359 \\
\hline Manual Dexterity & 23.013 & 35.913 & 25.143 & 30.744 & 27.832 \\
\hline Cramped Work Space & 22.580 & 33.128 & 22.882 & 17.883 & 22.172 \\
\hline Originality & 47.134 & 34.973 & 32.516 & 30.634 & 37.501 \\
\hline Social Perceptiveness & 51.154 & 38.138 & 40.148 & 37.994 & 43.163 \\
\hline Negotiation & 43.228 & 32.274 & 31.706 & 32.369 & 36.281 \\
\hline Persuasion & 46.133 & 34.616 & 35.193 & 34.408 & 38.88 \\
\hline Assist. \& caring for others & 49.183 & 38.703 & 46.508 & 37.087 & 42.972 \\
\hline US employment & 44948480 & 13736680 & 14150910 & 46584950 & 121110540 \\
\hline Share of US employment (\%) & 37 & 11 & 12 & 38 & 100.00 \\
\hline \multicolumn{6}{|c|}{$\begin{array}{l}\text { Note: The table reports on the mean characteristics of occupations weighted by US employment in the occupations. The shares of the occupations in the } \\
\text { four quadrants do not add up to } 100 \% \text { because occupations that lie exactly on the split lines are not assigned to any quadrant. Boldface values are above } \\
\text { the weighted average values for the total sample. }\end{array}$} \\
\hline Source: compiled by the authors. & & & & & \\
\hline
\end{tabular}

are different from "collapsing" occupations in that these occupations more strongly rely on non-routine manual and cognitive skills while their content faces strong transformation. For example, secretaries and administrative assistants below the executive level can be replaced by machines with less transformation of the tasks and therefore belong to the "collapsing" group. Moreover, "machine terrain" occupations are different from the "rising star" occupations in that they more strongly rely on (non-routine) skills that can be performed by new digital technologies thus making human workers in them increasingly redundant.

Last but not least, the "human terrain" occupations require above-average capability levels of "assisting and caring for others" and working in a "cramped workspace", while they have below-average levels for other computerization bottlenecks. Sample occupations in this group are, for instance, teacher assistants, customer service representatives, and funeral attendants, among others. Both digitalization impacts, transformative and destructive, are relatively low in these occupations.

In sum, the capabilities representing computerization bottlenecks are prevalent in the "rising star" occupations, whereas they are relatively unimportant in the "collapsing" occupations. "Machine terrain" occupations seem to rely more strongly on non-routine manual skills, such as manual and finger dexterity, which can potentially be automated in the future through significant transformations, while the automation bottleneck of "assisting and caring for others" requires human workers in "human terrain" occupations in the foreseeable future.

\section{Conclusions}

This paper conceptualizes the effects of the new wave of digitalization on occupations by proposing a map of occupations that differ from each other in terms of the impact level of destructive and transformative digitalization. While transformative digitalization changes the content of occupations without necessarily replacing human workers, destructive digitalization may make human workers obsolete, without necessarily transforming occupations. Mapping occupations in this way allows us to distinguish between four major groups of occupations, which we entitled "rising stars", "machine terrain", "human terrain", and "collapsing" occupations.

This distinction proves to be meaningful in the empirical analysis, which reveals that a substantial share of occupations that employ about $75 \%$ of the US workforce face either a high transformative, but low destructive impact of digitalization, or vice versa (each group accounts for about 37-38\% of total employment in the United States). A key difference between "rising stars" and "collapsing" occupations is that the former require higher levels of creative and social intelligence. Therefore, human workers cannot be replaced in these occupations in the near future and will work together with new AI technologies in transformed occupations, in contrast to the "collapsing" occupations, which require fewer of these skills and can therefore be more easily replaced by machines. Workers in the "rising stars" occupations will have to cope with substantial changes in their occupations, probably by means of acquiring further qualifications in order to remain competitive, even if the risk of replacement by machines is relatively low. 
Workers in "collapsing" occupations may need requalification to avoid potential unemployment.

Another substantial part of occupations, employing about $11 \%$ of workers, are confronted with the significant transformation of their occupational content due to AI, which puts these workers at risk of becoming redundant. Many of these occupations are characterized by relatively high levels of manual skills. Although workers in "machine terrain" occupations might also need to obtain further qualification to face the transformative changes in their current occupations, in the long run these workers might need to re-qualify themselves, since the risk of replacement is high.
Last but not least, about $12 \%$ of workers are employed in "human terrain" occupations that remain largely unaffected by digitalization. Their workplaces appear to be rather secure from the destructive effects of digitalization, but they do not seem to benefit directly from transformative digitalization that makes human workers more productive in their jobs. One of the key capabilities in these jobs is assisting and caring for others.

We thank Conor Hargrove for his excellent research assistance. Frank Fossen thanks the Ewing Marion Kauffman Foundation for their financial support of this research project. The contents of this publication are solely the responsibility of the authors.

\section{References}

Acemoglu D., Restrepo P. (2019) The Wrong Kind of AI? Artificial Intelligence and the Future of Labor Demand (IZA Discussion Paper 12292), Bonn: Institute of Labor Economics.

Arntz M., Gregory T., Zierahn U. (2017) Revisiting the Risk of Automation. Economics Letters, vol. 159, pp. 157-160.

Autor D.H. (2015) Why Are There Still So Many Jobs? The History and Future of Workplace Automation. Journal of Economic Perspectives, vol. 29, no 3, pp. 3-30.

Brynjolfsson E., McAfee A. (2014) The Second Machine Age: Work, Progress, and Prosperity in a Time of Brilliant Technologies (1st ed.), New York: W. W. Norton \& Company.

Brynjolfsson E., Mitchell T., Rock D. (2018) What Can Machines Learn and What Does It Mean for Occupations and the Economy? American Economic Association Papers and Proceedings, vol. 108, pp. 43-47.

Chang J.-H., Huynh P. (2016) ASEAN in Transformation: The Future of Jobs at Risk of Automation (Bureau for Employers' Activities Working Paper no 9), Geneva: International Labour Organization.

Felten E.W., Raj M., Seamans R. (2018) A Method to Link Advances in Artificial Intelligence to Occupational Abilities. American Economic Association Papers and Proceedings, vol. 108, pp. 54-57.

Fossen F.M., Sorgner A. (2019) New Digital Technologies and Heterogeneous Employment and Wage Dynamics in the United States: Evidence from Individual-level Data (IZA Discussion Paper 12242), Bonn: Institute of Labor Economics.

Frey C.B., Osborne M.A. (2017) The Future of Employment: How Susceptible Are Jobs to Computerization? Technological Forecasting and Social Change, vol. 114, pp. 254-280.

Manyika J., Lund S., Chui M., Bughin J., Woetzel J., Batra P., Ko R., Sanghvi S. (2017) Jobs Lost, Jobs Gained: Workforce Transitions in a Time of Automation, New York: McKinsey Global Institute.

Sorgner A. (2017) Jobs at Risk!? Effects of Automation of Jobs on Occupational Mobility. Foresight and STI Governance, vol. 11, no 3, pp. 37-48. DOI: 10.17323/2500-2597.2017.3.37.48.

Sorgner A., Bode E., Krieger-Boden C. (2017) The Effects of Digitalization on Gender Equality in the G20 Economies (E-book), Kiel: Kiel Institute for the World Economy. Available at: https://www.ifw-kiel.de/pub/e-books/digital_women-final_report.pdf, accessed 25.04.2019. 